\title{
One-Input Three-Output Current-Mode Universal Filter Using Translinear Current Conveyors
}

\author{
Montree Kumngern ${ }^{1}$
}

\begin{abstract}
This paper presents a new current-mode universal filter with one-input three-output employing three translinear current conveyors and two grounded capacitors. The proposed filter provides low-pass, band-pass, high-pass current response with high output impedance output which can be directly connected for current-mode circuit. The band-pass and all-pass filters can also be obtained. The parameters $\omega_{o}$ and $Q$ can be controlled separately and electronically by the bias currents of current conveyors. For realizing all filtering functions, no passive and active matching conditions are required. The active and passive sensitivities are low. The characteristic of the proposed circuit can be confirmed by SPICE simulations.
\end{abstract}

Keywords-Universal filter, current-mode circuit, translinear current conveyor, analog circuit.

\section{INTRODUCTION}

In recent years, the design and implementation of currentmode active filters using second-generation current conveyors (CCIIs) have received considerable attention owing to the fact that their bandwidth, linearity, dynamic range performances are better than those of their operational amplifier (op-amp) based counterparts [1].

The current-mode filters can be connected to the next stage without using additional current buffer, if it possesses the property of high output impedance. On the other hand, the filter is attractive for monolithic integrated circuit (IC) implementation, if it employs grounded capacitors [2]. The second-order universal filter plays an important role in the fields of electronic measurement, communication, automatic control and neural networks. Therefore, a number of universal filter that can realize second-order low-pass (LP), band-pass (BP), high-pass (HP), band-stop (BS) and all-pass (AP) filters simultaneously, have been proposed [3]-[10]. Several currentmode CCII-based universal filters realizing current transfer functions with single-input three-output (SITO) have been presented [5]-[12]. By interconnection of relevant output currents, LP, BP, HP, BS and AP filters can be obtained from the same circuit configuration. The SITO current-mode universal filters in [5]-[8] requires four CCIIs. Abuelma'atti and Khan [9] proposed a current-mode SITO universal filter circuit using three CCIIs, one OTA, two grounded resistors and three grounded capacitors. The current-mode SITO universal filter in [10] uses three CCIIs, two grounded resistors and two grounded capacitors. Moreover, these CCIIbased universal filters are not offered an electronic tuning

1 Lecturer, Department of Telecommunications Engineering, Faculty of Engineering, King Mongkut's Institute of Technology Ladkrabang, Bangkok 10250, THAILAND (e-mail: kkmontre@gmail.com) capability, sine its parasictic resistance at X-terminal $\left(R_{x}\right)$ of CCII cannot be electronically tuned.

By introducing of second-generation current-controlled current conveyor (CCCII) [11], the CCII applications can be extended to the domain of electronically adjustable functions. Several current-mode CCCII-based SITO and SIMO filters have been proposed [12]-[23]. However, these filters suffer from one or more of the following disadvantages: (i) not provide orthogonal control of parameters $\omega_{0}$ and Q [12]-[22], (ii) not provide high output impedance [14], [16], [12], [18], (iii) employment floating capacitor [18], and (iv) employment excessive active elements [13], [24].

In this paper, a new current-mode current-controlled universal filter employing only three CCCIIs and two grounded capacitors which is advantageous in view of integrated circuit implementation is proposed. The proposed circuit can realize simultaneously LP, BP and HP current responses with high output impedance and low input impedance, thus the realization of BS and AP functions requires no additional buffer circuits. The parameters $\omega_{o}$ and $Q$ can be orthogonally controlled. Moreover, by using the CCCII with adjustable current gain, the high-Q filter and the current gain of transfer function can be obtained. No critical matching condition is required for realizing all filtering functions. The active and passive sensitivities are low. SPICE simulation results are included to verify new circuit.

\section{PROposed CIRCUIT}

The CCCII can be used to apply several analog circuits such as amplifiers, filters, oscillators and nonlinear circuits. The well-known schematic of CCCII implemention with bipolar transistor is shown in Fig. 1 [11]. This device has three terminals ( $\mathrm{Y}, \mathrm{X}$ and $\mathrm{Z}$ terminals) and $\mathrm{I}_{0}$ is the bias current. From Fig. 1, voltage gain between terminals $\mathrm{Y}$ and $\mathrm{X}$ and current gain between terminals $\mathrm{X}$ and $\mathrm{Z}$ are an unity.

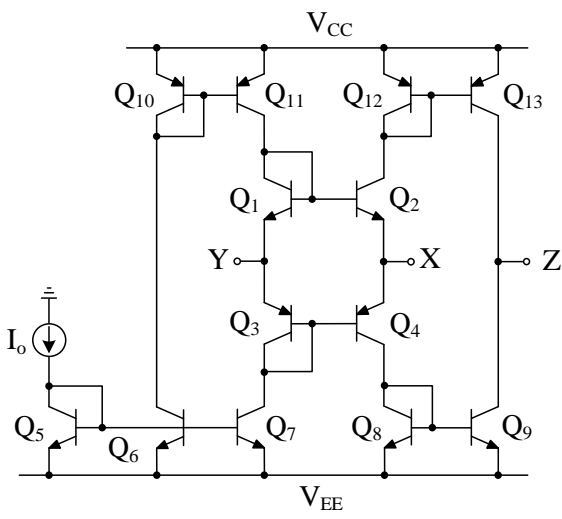

Fig. 1 Schematic implementation for CCCII. 


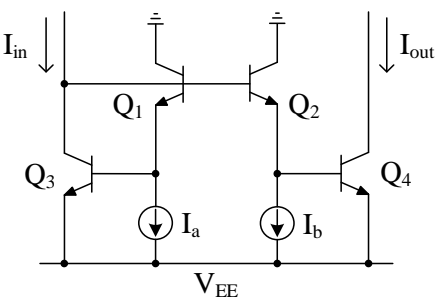

(a)

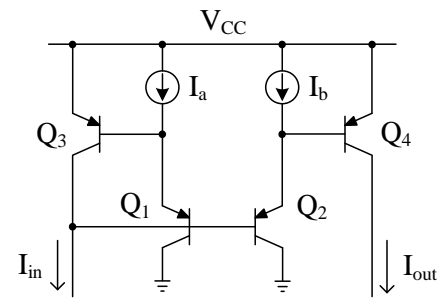

(b)

Fig. 2 Current mirrors with adjustable current gain: (a) positive-type, (b) negative-type.

Terminals $\mathrm{Y}$ and $\mathrm{Z}$ possess high impedance level whereas $\mathrm{X}$ terminal has finite resistance $\left(R_{x}\right)$ that can be given as

$$
R_{X}=\frac{V_{T}}{2 I_{o}} .
$$

$R_{X}$ is the parasitic resistance of a translinear mixed loop $\left(Q_{1}\right.$ to $Q_{4}$ ) that can be controlled by bias current $I_{o}$, when $V_{T}$ is the thermal voltage $\left(\cong 26 \mathrm{mV}\right.$ at $\left.27^{\circ} \mathrm{C}\right)$.

The CCCII with adjustable current gain can be obtained by modifying the original circuit of the CCCII in Fig. 1 and adding current mirror with adjustable gain as shown in Fig. 2 [24]. The current gain can be obtained at $\mathrm{Z}$ terminal. Also, the multiple-output CCCII can be obtained by adding additional current mirrors and cross-coupled current mirrors to obtain plus and minus type outputs [25]. Fig. 3 shows the schematic of the multiple-output plus/minus CCCII with adjustable current gain [26]. In this figure, CCCII with adjustable current gain has a unity voltage gain between terminals $\mathrm{Y}$ and $\mathrm{X}$ and current gain $k$ between terminals $\mathrm{X}$ and $\mathrm{Z}$. The latter property makes it different from a conventional CCCII. A few current conveyors with adjustable gain are proposed [27]-[29]. However, the structures [28], [29] are not suitable for high-Q filter, because CMOS-based circuits are limited tunable range of current gain. The schematic of CCCII with adjustable current gain in Fig. 3 can be characterized by

$$
\left(\begin{array}{c}
I_{Y} \\
V_{X} \\
I_{Z} \\
I_{Z k}
\end{array}\right)=\left(\begin{array}{cccc}
0 & 0 & 0 & 0 \\
1 & R_{X} & 0 & 0 \\
0 & \pm 1 & 0 & 0 \\
0 & \pm k & 0 & 0
\end{array}\right)\left(\begin{array}{c}
V_{Y} \\
I_{X} \\
V_{Z} \\
V_{Z k}
\end{array}\right) .
$$

The current gain $k$ of CCCII can be given by [25].

$$
k=\frac{I_{a}}{I_{b}} .
$$

Then, the signal current is amplified by the factor $k$ and this factor can be varied linearly controlled by adjusting the bias currents $I_{a}$ and $I_{b}$.

The proposed current-mode universal filter with one-input terminal and three-output is shown in Fig. 4. It consists of three CCCIIs and two grounded capacitors. It should be noted that the use of grounded capacitor makes the circuit suitable for IC implementation [2]. Using (2) and nodal analysis, the current transfer functions of Fig. 4 can be expressed by

$$
\begin{aligned}
& \frac{I_{L P}}{I_{\text {in }}}=k_{3} \frac{1}{s^{2} R_{x 1} R_{x 2} C_{1} C_{2}+s R_{x 2} C_{2} k_{1}+1} \\
& \frac{I_{B P}}{I_{\text {in }}}=-k_{3} \frac{s R_{x 2} C_{2} k_{1}}{s^{2} R_{x 1} R_{x 2} C_{1} C_{2}+s R_{x 2} C_{2} k_{1}+1} \\
& \frac{I_{H P}}{I_{\text {in }}}=k_{3} \frac{s^{2} R_{x 1} R_{x 2} C_{1} C_{2}}{s^{2} R_{x 1} R_{x 2} C_{1} C_{2}+s R_{x 2} C_{2} k_{1}+1} .
\end{aligned}
$$

There, the circuit provides a non-inverting LP filter at $I_{L P}$, an inverting $\mathrm{BP}$ signal at $\mathrm{I}_{\mathrm{BP}}$ and a non-inverting $\mathrm{HP}$ signal at $I_{H P}$. Because the impedance of $\mathrm{I}_{\mathrm{LP}}, \mathrm{I}_{\mathrm{BP}}$ and $\mathrm{I}_{\mathrm{HP}}$ terminals are high impedance level ( $\mathrm{Z}$ terminal) of CCCII, therefore terminals $I_{L P}, I_{B P}$, and $I_{H P}$ can be directly connected to the next stage without buffer circuit requirements. In addition, the input $I_{\text {in }}$ is applied to the low impedance level of CCCII (X terminal). Also, by appropriately connecting the outputs $I_{L P}$, $I_{B P}$, and $I_{H P}$, BS and AP current responses can be obtained; i.e. $I_{B S}=I_{H P}+I_{L P}$ and $I_{A P}=I_{L P}+I_{B P}+I_{H P}$. The current transfer functions of BS and AP filters can be expressed by

$$
\begin{aligned}
& \frac{I_{B S}}{I_{\text {in }}}=k_{3} \frac{s^{2} R_{x 1} R_{x 2} C_{1} C_{2}+1}{s^{2} R_{x 1} R_{x 2} C_{1} C_{2}+s R_{x 2} C_{2} k_{1}+1} \\
& \frac{I_{A P}}{I_{\text {in }}}=k_{3} \frac{s^{2} R_{x 1} R_{x 2} C_{1} C_{2}-s R_{x 2} C_{2} k_{1}+1}{s^{2} R_{x 1} R_{x 2} C_{1} C_{2}+s R_{x 2} C_{2} k_{1}+1}
\end{aligned}
$$

where $k_{1}$ and $k_{3}$ are the current gain of $\mathrm{CCCII}_{1}$ and $\mathrm{CCCII}_{3}$, respectively, $R_{x 1}$ and $R_{x 2}$ are the parasitic resistance at terminal $\mathrm{X}$ of $\mathrm{CCCII}_{1}$ and $\mathrm{CCCII}_{2}$, respectively. The parameters $\omega_{o}$ and $Q$ of all filtering functions can be given by

$$
\omega_{o}=\frac{1}{\sqrt{R_{x 1} R_{x 2} C_{1} C_{2}}}
$$

and

$$
Q=\frac{1}{k_{1}} \sqrt{\frac{R_{x 2} C_{2}}{R_{x 1} C_{1}}} .
$$

Using (3), the current gain $k_{3}$ is $I_{a 3} / I_{b 3}$. Then, the current gain $k_{3}$ of the transfer functions can be controlled by adjusting the ratio $I_{a 3} / I_{b 3}$. Using (1), the resistances $R_{x 1}=V_{T} / 2 I_{o 1}$ and $R_{X 2}$ $=V_{T} / 2 I_{o 2}$ can be given. Letting $R_{X 1}=R_{X 2}$ and $C_{1}=C_{2}$, (10) becomes

$$
Q=\frac{I_{b 1}}{I_{a 1}}
$$




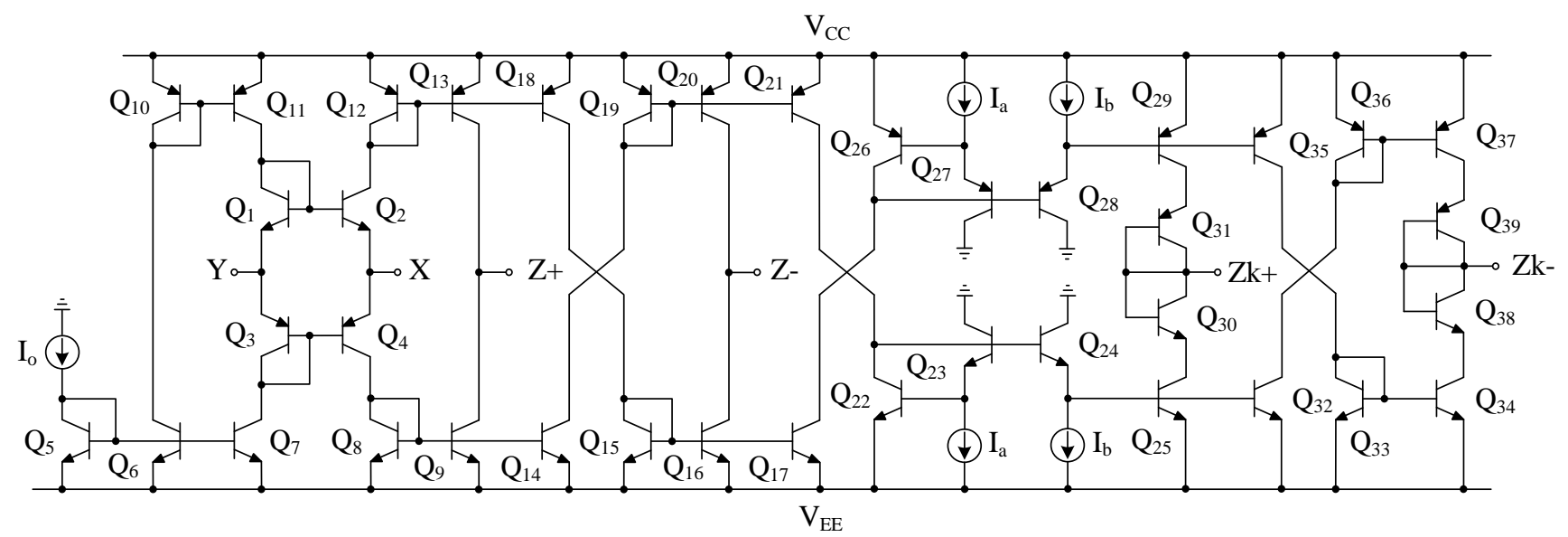

(a)

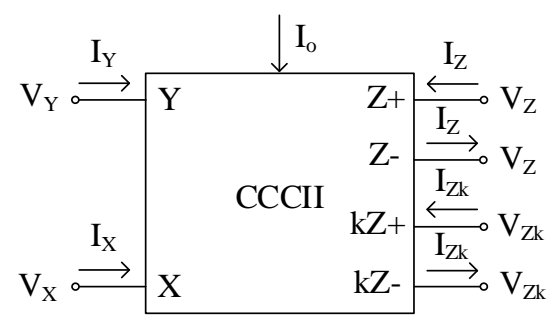

(b)

Fig. 3 CCCII with controlled circuit gain: (a) bipolar implementation, (b) electrical symbol.

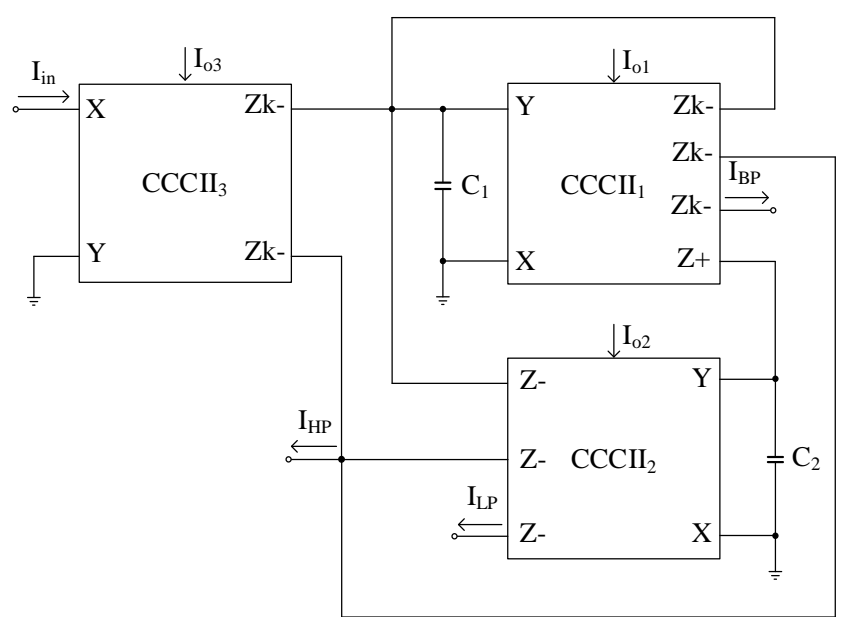

Fig. 4 Proposed universal filter with one-input three-output.

where $I_{a 1}$ and $I_{b 1}$ are the bias currents of $\mathrm{CCCII}_{1}$. It is evident from (9) and (11) that the parameter $\omega_{0}$ for all filter responses can be electronically tuned by varying $I_{01}$ and $I_{02}$ without affecting the parameter $Q$. For the $Q$-value of filter, it can be controlled linearly and separately by adjusting the ratio $I_{b 1} / I_{a 1}$. Moreover, the $Q$-value is temperature independent. The current gain of all transfer functions can be controlled using $k_{3}$ of $\mathrm{CCCII}_{3}$.

\section{NON-IDEAL EFFECTS}

To consider the non-ideal effect of CCCII, taking the nonidealities of the CCCII with adjustable current gain into account, the relationship of voltage and current can be expressed as

$$
\left(\begin{array}{c}
I_{Y} \\
V_{X} \\
I_{Z} \\
I_{Z k}
\end{array}\right)=\left(\begin{array}{cccc}
0 & 0 & 0 & 0 \\
\alpha_{j} & R_{X} & 0 & 0 \\
0 & \pm \beta_{j} & 0 & 0 \\
0 & \pm \beta_{k j} k_{j} & 0 & 0
\end{array}\right)\left(\begin{array}{c}
V_{Y} \\
I_{X} \\
V_{Z} \\
V_{Z k}
\end{array}\right)
$$

where $\alpha_{j}=1-\varepsilon_{v}$ and $\varepsilon_{v}\left(\varepsilon_{v} \ll 1\right)$ is the voltage tracking error from Y terminal to X terminal of the $j$-th CCCII, $\beta_{j}=1-\varepsilon_{i}$ and $\varepsilon_{i}\left(\varepsilon_{i} \ll 1\right)$ is the output current tracking error of the $j$-th CCCII. Reanalysis the proposed filter of Fig. 4 using (12), the non-ideal natural frequency $\left(\omega_{o n}\right)$ and non-ideal quality factor $\left(Q_{n}\right)$ can be expressed as

$$
\omega_{\text {on }}=\sqrt{\frac{\alpha_{1} \alpha_{2} \beta_{1} \beta_{2}}{R_{x 1} R_{x 2} C_{1} C_{2}}}
$$

and

$$
Q_{n}=\frac{1}{k_{1} \beta_{k 1}} \sqrt{\frac{R_{x 2} C_{2}}{R_{x 1} C_{1}} \frac{\alpha_{1} \beta_{1}}{\alpha_{2} \beta_{2}}}
$$

From (13) and (14), it indicates that the voltage and current tracking errors slightly change the natural frequency and quality factor. However, the natural frequency and quality factor can still be orthogonally controlled. The incremental sensitivities of the parameters $\omega_{0}$ and $Q$ are calculated as Table I. It is evident from Table I that all the active and 
passive sensitivities are equal and less than unity in magnitude. Therefore, the proposed filter exhibits a low sensitivity performance.

TABLE I

SENSITIVITIES OF CIRCUIT COMPONENTS

\begin{tabular}{|c|c|c|}
\hline \hline $\boldsymbol{x}$ & $\boldsymbol{S}_{\boldsymbol{x}}^{\boldsymbol{\omega}_{\mathbf{0}}}$ & $\boldsymbol{S}_{\boldsymbol{x}}^{\boldsymbol{Q}}$ \\
\hline$R_{x 1}$ & -0.5 & -0.5 \\
\hline$R_{x 2}$ & -0.5 & 0.5 \\
\hline$C_{1}$ & -0.5 & -0.5 \\
\hline$C_{2}$ & -0.5 & 0.5 \\
\hline$\alpha_{1}$ & 0.5 & 0.5 \\
\hline$\alpha_{2}$ & 0.5 & -0.5 \\
\hline$\beta_{1}$ & 0.5 & 0.5 \\
\hline$\beta_{2}$ & 0.5 & -0.5 \\
\hline$k_{1}$ & 0.0 & -1.0 \\
\hline$\beta_{k 1}$ & 0.0 & -1.0 \\
\hline
\end{tabular}

\section{Simulation Results}

In order to verify the characteristics of the proposed filter in Fig. 4, SPICE simulations have been carried out. The CCCIIs in Fig. 1 and Fig. 3 were performed with the transistor model of PR100N and NP100N of the bipolar arrays ALA400 from AT\&T [30] and the supply voltages are gien as $V_{C C}=-V_{E E}=3$ V. For example design, $C_{1}=C_{2}=10 \mathrm{nF}$ was given. Fig. 5 shows the simulated frequency responses of the proposed filter with the bias currents $I_{o 1}=I_{o 2}=100 \mu \mathrm{A}, I_{o 3}=250 \mu \mathrm{A}$ and $I_{a 1}=I_{b 1}=I_{a 3}=I_{b 3}=50 \mu \mathrm{A}$. This setting has been designed to obtain LP, BP, and HP current responses with $f_{\mathrm{o}} \cong 127 \mathrm{kHz}$, $Q=1$ and $k_{3}=1$. By connecting of relevant output currents, the simulation results of BS (i.e. $I_{L P}+I_{H P}$ ) and AP (i.e. $I_{L P}+$ $\left.I_{B P}+I_{H P}\right)$ filters can be shown in Fig. 6 and Fig. 7, respectively. Form Fig. 5 to Fig. 7, it can be confirmed that the proposed filter provides five standard biquadratic filtering functions into one topology. Fig. 8 shows the simulated BP filter response when the bias currents $I_{o}$ (i.e. $I_{o}=I_{o 2}=I_{o 3}$ ) were simultaneously adjusted for the values of 50, 100, 200 and 500 $\mu \mathrm{A}$ while keeping $I_{a 1}=I_{b 1}=I_{a 3}=I_{b 3}=50 \mu \mathrm{A}$ constant for $Q=$ 1 and $k_{3}=1$. This result was confirmed by (9).

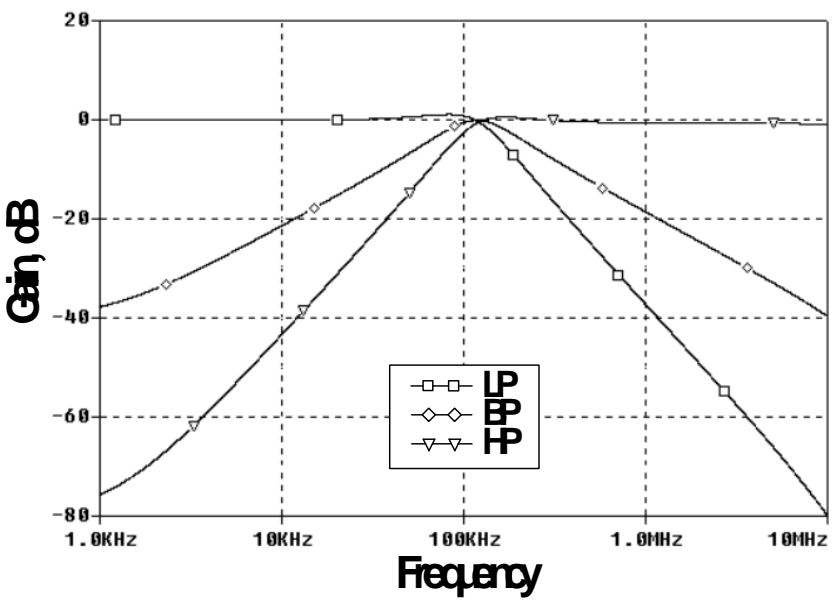

Fig. 5 Simulated LP, BP, and HP of the proposed filter.

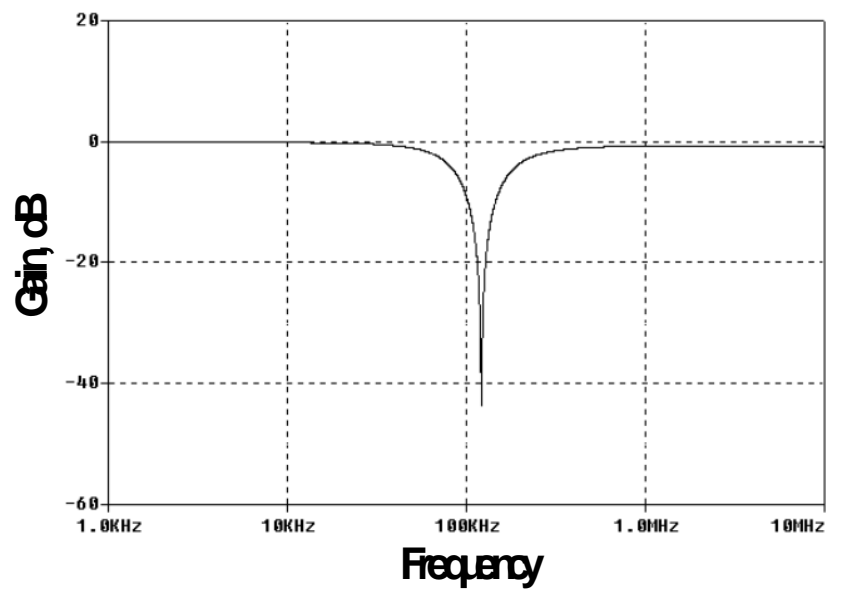

Fig. 6 Simulated frequency response of BS filter.

\section{Gain CB Phæ, degre}

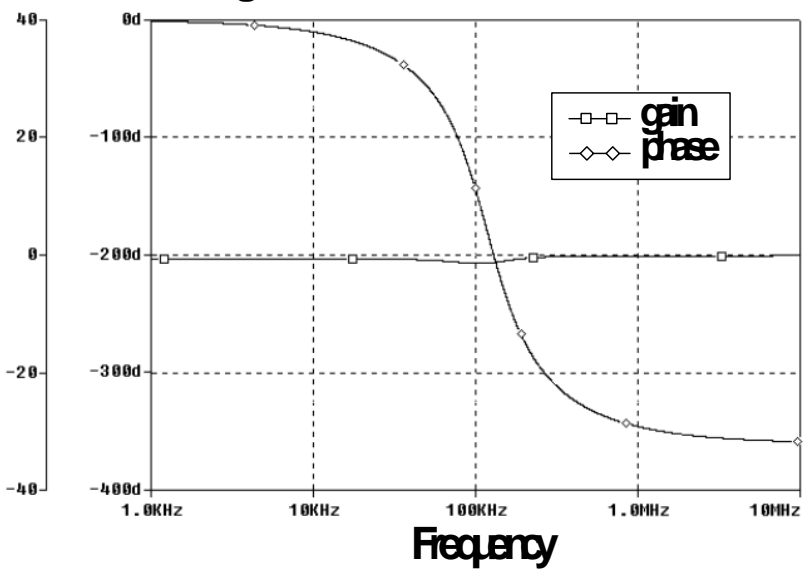

Fig. 7 Simulated frequency and phase responses of AP filter.

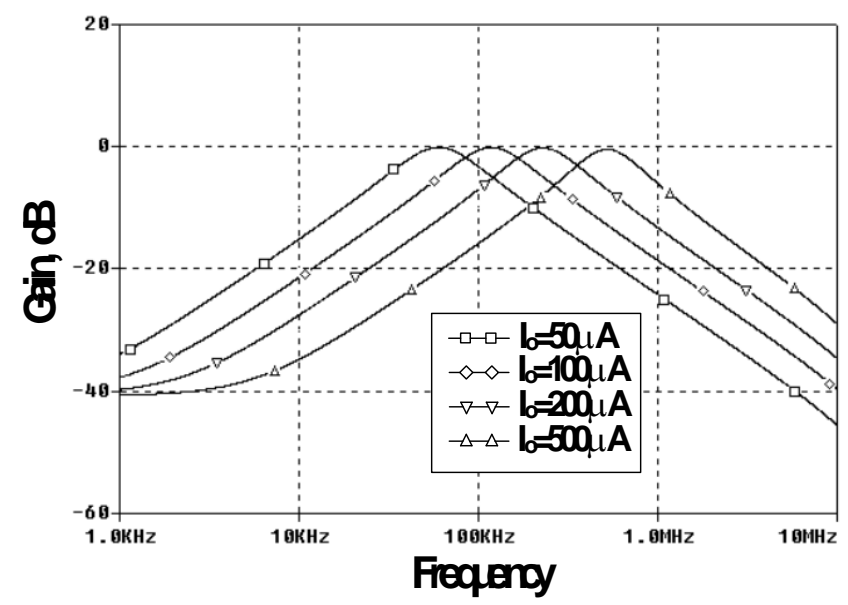

Fig. 8 Simulated frequency response of BP filter when $I_{0}$ is varied.

To demonstrate the current gain of current conveyor tuning $Q$, the bias currents were set constant as $I_{o 1}=I_{o 2}=I_{o 3}=100$ $\mu \mathrm{A}, I_{a 1}=I_{a 3}=I_{b 3}=50 \mu \mathrm{A}$ and bias current $I_{b 1}$ was varied. The corresponding current characteristics of BP filter when $I_{b 1}$ was varied shown in Fig. 9. It can be noted that high value of the $Q$ 
can be obtained by using high value of $I_{b 1}$. This result is confirmed by (11). By adjusting the current gain $k_{3}$ of $\mathrm{CCCII}_{3}$ in Fig. 4, the the current gain of all filters can be adjusted. The bias current $I_{a 3}$ was adjusted for the values of $50,300,500$, and $1000 \mu \mathrm{A}$ and keeping $I_{a 1}=I_{b 1}=I_{b 3}=50 \mu \mathrm{A}, I_{o 1}=I_{o 2}=I_{o 3}$ $=100 \mu \mathrm{A}$ constant. The frequency response of LP filter was used to test and its frequency response with different gain was shown in Fig. 10.

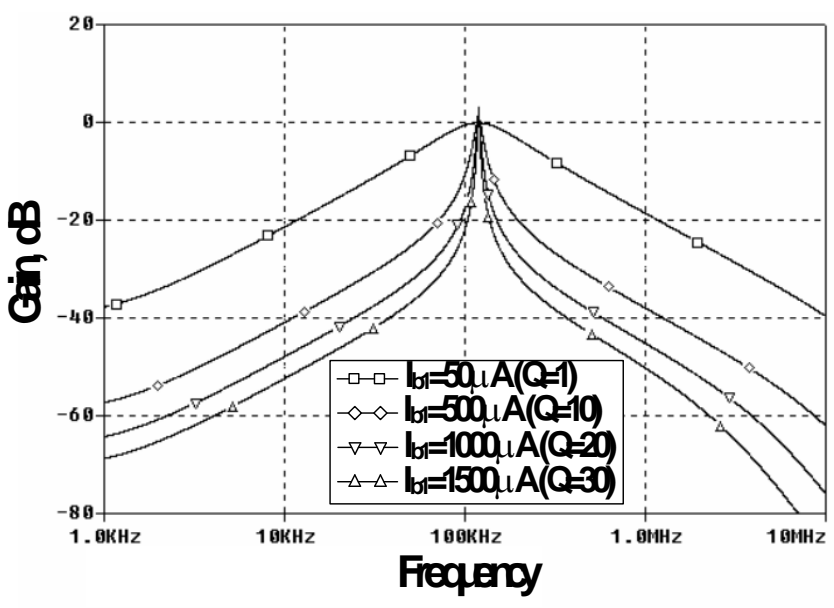

Fig. 9 Simulated frequency responses of BP filter when $I_{b 1}$ is varied.

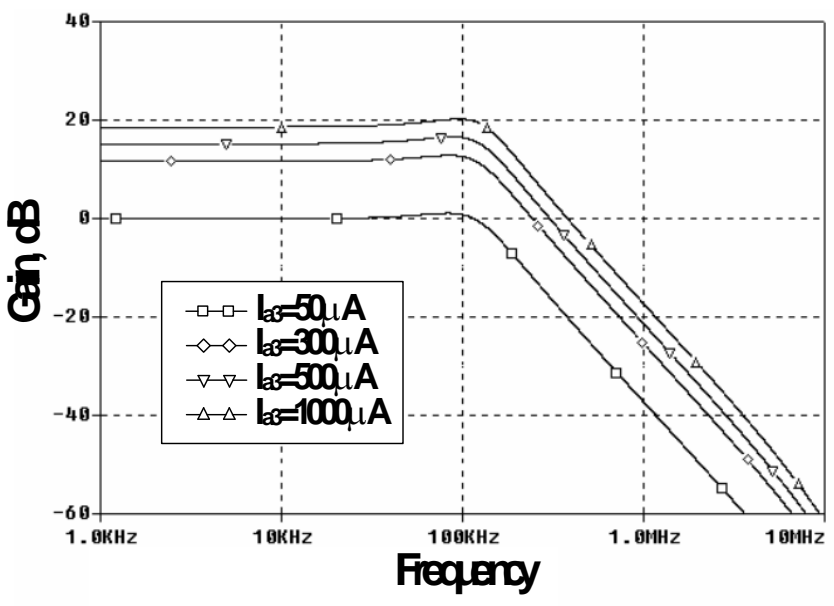

Fig. 10 Simulated frequency response of LP filter with different gain.

\section{CONCLUSION}

A new one-input three-outputs current-mode universal filter employing three translinear current conveyors and two grounded capacitors, which is suitable for IC implementation, was proposed. The circuit possesses the following properties: (i) ability for realizing LP, BP, HP, BS and AP current responses without component-matching condition; (ii) high output impedance and low impedance impedance which is suitable for cascading in current-mode circuits; (iii) low active and passive sensitivities; (iv) independent control for parameters $\omega_{0}$ and $Q$; (v) adjustable gain of all filtering functions. Furthermore, high Q-value of filter can be obtained by adjusting the current gain of CCCII. Simulation results are given to demonstrate the effectiveness of new schemes.

\section{REFERENCES}

[1] G.W. Roberts and A.S. Sedra, "All-Current-Mode Frequency Selective Circuits,” Electronics Letters, Vol. 25, No. 12, pp. 759-761, 1989.

[2] M. Bhusan and R.W. Newcomb, "Grounding of Capacitors in Integrated Circuits,” Electronics Letters, Vol. 3, No. 4, pp. 148-149, 1967.

[3] T. Tsukutani, Y. Sumi, and N. Yabuki, "Novel Current-Mode Biquadratic Circuit Using Only Plus Type DO-Dvccs and Grounded Passive Components," International Journal of Electronics, Vol. 94, No. 12, pp. 1137-1146, 2007.

[4] W. Chunhus, L. Haiguang, and Z. Yan, "Universal Current-Mode Filter With Multiple Inputs and One Output Using MOCCII and MO-CCCA,” International Journal of Electronics and Communications, Vol. 63, No. 6, pp. 448-453, 2009.

[5] R. Senani, "New Current-Mode Biquad Filter," International Journal of Electronics, Vol. 73, No. 4, pp. 735-742, 1992.

[6] C.M. Chang, "Universal Active Current Filter with Single Input and Three Outputs Using CCIIs,” Electronics Letters, Vol. 29, No. 22, pp. 1932-1933, 1993.

[7] C.M. Chang, "Novel Universal Current-Mode Filter with Single Input and Three Outputs Using Only Five Current Conveyors," Electronics Letters, Vol. 29, No. 23, pp. 2005-2007, 1993.

[8] M. Soliman, "Current Conveyor Filters: Classification and Review," Microelectronics Journal, Vol. 29, No. 3, pp. 133-149, 1998.

[9] M.T. Abuelma'atti and M.H. Khan, "Low Component Current-Mode Universal Filter,” Electronics Letters, Vol. 31, No. 25, pp. 2160-2162, 1995.

[10] H.Y. Wang and C.T. Lee, "Versatile Insensitive Current-Mode Universal Biquad Implementation Using Current Conveyor,” IEEE Transactions on Circuits and Systems-II, Vol. 48, No. 4, pp. 409-413, 2001.

[11] A. Fabre, O. Saaid, F. Wiest, and C. Boucheron, "Current Controlled Bandpass Filter Based on Translinear Conveyors," Electronics Letters, Vol. 31, No. 20, pp. 1727-1728, 1995.

[12] W. Kiranon, J. Kesorn, W. Sangpisit, and N. Kamprasert, "Electronically Tunable Multifunctional Translinear-C Filter and Oscillator,” Electronics Letters, Vol. 33, No. 7, pp. 573-574, 1997.

[13] M.T. Abuelma'atti and N.A. Tasadduq, "A Novel Single-Input Multiple-Output Current-Mode Current-Controlled Universal Filter," Microelectronics Journal, Vol. 29, No. 11, pp. 901-905, 1998.

[14] M.T Abuelma'atti and N.A. Tasadduq, "New Current-Mode CurrentControlled Filters Using the Current-Controlled Conveyor," International Journal of Electronics, Vol. 85, No. 4, pp. 483-488, 1998.

[15] M.T. Abuelma'atti and N.A. Tasaduq, "Universal Current-Controlled Current-Mode Filter Using the Multiple-Output Translinear Current Conveyor," Frequenz, Vol. 52, No. 11-12, pp. 252-254, 1998.

[16] I.A. Khan and M.H. Zaidi, "Multifunction Translinear-C Current-Mode Filter," International Journal of Electronics, Vol. 87, No. 9, pp. 10471051, 2000.

[17] S. Minaei and S. Turkoz, "New Current-Mode Current-Controlled Universal Filter with Single Input and Three Outputs," International Journal of Electronics, Vol. 88, No. 3, pp. 333-337, 2001.

[18] M. Sagbas and K. Fidanboylu, "Electronically Tunable Current-Mode Second-Order Universal Filter Using Minimum Elements," Electronics Letters, Vol. 40, No. 1, pp. 2-4, 2004.

[19] S. Minaei and S. Turkoz, "Current-Mode Electronically Tunable Universal Filter Using Only Plus-Type Current Controlled Conveyors and Grounded Capacitors,” ETRI Journal, Vol. 26, No. 4, pp. 292-296, 2004.

[20] N.A. Shah, M.F. Rather, and S. Z. Iqbal, "SITO Electronically Tunable High Output Impedance Current-Mode Universal Filter,” Analog Integrated Circuits Signal Processing, Vol. 47, No. 3, pp. 335-338, 2006.

[21] C. Wang, H. Liu, Y. Zhao, "A New Current-Mode Current-Controlled Universal Filter Based on CCCII $( \pm)$," Circuits, Systems and Signal Processing, Vol. 27, No. 5, pp. 673-682, 2008. 
[22] M. Sripunchayanun and W. Jaikla, "Cascadable Current-Mode Biquad Filter and Quadrature Oscillator Using DO-CCCIIs and OTA,” Circuits Systems Signal Processing, Vol. 27, pp. 113-122, 2008.

[23] N. Pandy, S.K. Paul, and S.B. Jain, "A New Electronically Tunable Current Mode Universal Filter Using MO-CCCII,” Analog Integrated Circuits and Signal Processing, Vol. 58, No. 2, pp. 171-178, 2009.

[24] C. Toumazou, F.J. Lidgey, and D.G. Haig, Analogue IC Design: The Current-Mode Approach, London, UK: Peter Peregrinus, 1990.

[25] M.T. Abuelma'atti and M.A. Al-Qahtani, “A New Current-Controlled Multiphase Sinusoidal Oscillator Using Translinear Current Conveyor,” IEEE Transactions on Circuits and Systems-II, Vol. 45, No. 7, pp. 881885, 1998.

[26] M. Kumngern, W. Jongchanavawat, and K. Dejhan, "New Electronically Tunable Current-Mode Universal Biquad Filter Using Translinear Current Conveyors,” International Journal of Electronics, Vol. 97, No. 5, pp. 511-523, 2010.
[27] A. Fabre, N. Mimeche, "Class A/AB Second Generation Current Conveyor with Controlled Current Gain,” Electronics Letters, Vol. 43, pp. 82-91, 1996.

[28] W. Surakampontorn, and K. Kumwachara, "CMOS-Based Electronically Tunable Current Conveyor,” Electronics Letters, Vol. 28, No. 14, pp. 1316-1317, 1992.

[29] S. Mimaei, O. K. Sayin, and H. Kuntman, “A New CMOS Electronically Tunable Current Conveyor and Its Application to Current-Mode Filters,” IEEE Transactions on Circuits and Systems-I, Vol. 53, No. 7, pp. 1448-1458, 2006.

[30] D.R. Frey, "Log Domain Filter: An Approach to Current Mode Filtering," IEE Proceedings, Part G, of Circuits, Devices and Systems, Vol. 140, No. 6, pp. 406-416, 1993. 